\title{
História da Análise Matemática e Desenvolvimento Cognitivo
}

\author{
History of Mathematical Analysis and Cognitive Development
}

\author{
Vinícius Weite Thomé* \\ ORCID iD 0000-0003-2878-2705 \\ Mariana Lima Duro** \\ ORCID iD 0000-0001-5492-4098 \\ Carina Loureiro Andrade ${ }^{* * *}$ \\ ORCID iD 0000-0003-1560-2197
}

\begin{abstract}
Resumo
Apresenta-se aqui esta pesquisa teórica que contém uma hipótese sobre a construção histórica dos conceitos de análise matemática à luz da epistemologia genética, com o propósito de obter conclusões sobre a aprendizagem desta área. Conforme a questão de pesquisa, "como se estruturam os saberes relacionados à análise matemática?", objetivou-se compreender o processo de construção dos conhecimentos de análise real na história, comparando ao desenvolvimento cognitivo do sujeito, sob perspectiva da epistemologia genética. Para isso, estudou-se a história da Matemática, a partir de suas principais referências, mais a teoria de Piaget. Como resultado, observou-se que o percurso que culminou na formalização atual da análise, ocorreu em quatro etapas: desenvolvimento do cálculo diferencial e integral; organização do cálculo; análise do cálculo; e a aritmetização da análise. Para cada uma dessas etapas foram encontradas semelhanças conceituais com os estádios de desenvolvimento cognitivo, sendo diferenciadas por seu nível de conceituação. Concluiu-se que a aprendizagem de análise se dá por meio das tomadas de consciência sucessivas, que culminam em conceituação. Então, o ato de apresentar axiomas e estabelecer propriedades e teoremas a partir deles não consiste em potencial atividade de ensino, exceto para aqueles estudantes que já alcançaram o patamar cognitivo necessário para realizar essas assimilações. Para aqueles que ainda não o alcançaram, faz-se necessário agir sobre os objetos matemáticos e tomar consciência dos instrumentos desta ação para a sua compreensão. Contribuiu-se com as discussões acerca da Educação Matemática no Ensino Superior, favorecendo democratização do aprendizado de Matemática em todos os níveis, incluindo os mais formais.
\end{abstract}

Palavras-chave: Aprendizagem de Matemática no Ensino Superior. Análise Real. História da Matemática. Epistemologia Genética.

\footnotetext{
* Licenciado em Matemática pelo Instituto Federal de Educação, Ciência e Tecnologia do Rio Grande do Sul (IFRS). Mestrando em Matemática pela Universidade Federal do Rio Grande do Sul (UFRGS), Porto Alegre, Rio Grande do Sul, Brasil. Endereço para correspondência: Rua Fernando Pessoa, 40, quadra 9, Estância Velha, Canoas, Rio Grande do Sul, Brasil, CEP 92032-700. E-mail: viniweitethome @ gmail.com.

** Doutora em Educação pela Universidade Federal do Rio Grande do Sul (UFRGS). Professora no Instituto Federal de Educação, Ciência e Tecnologia do Rio Grande do Sul (IFRS), Canoas, Rio Grande do Sul, Brasil. Endereço para correspondência: Rua Dra. Maria Zélia Carneiro de Figueiredo, 870, Igara, Canoas, Rio Grande do Sul, Brasil, CEP 92412-240. E-mail: mariana.duro@canoas.ifrs.edu.br.

*** Doutora em Matemática Aplicada pela Universidade Federal do Rio Grande do Sul (UFRGS). Professora no Instituto Federal de Educação, Ciência e Tecnologia do Rio Grande do Sul (IFRS), Canoas, Rio Grande do Sul, Brasil. Endereço para correspondência: Rua Dra. Maria Zélia Carneiro de Figueiredo, 870, Igara, Canoas, Rio Grande do Sul, Brasil, CEP 92412-240. E-mail: carina.andrade@ canoas.ifrs.edu.
} 


\begin{abstract}
This research discusses the historical construction of mathematical analysis concepts in the light of genetic epistemology, to obtain conclusions about the learning in this area. According to the research problem "How is structured knowledge related to mathematical analysis?", we aim to understand the process of constructing real knowledge analysis, in history and comparing the cognitive subject development, according to the genetic epistemology perspective. For this, we studied the history of mathematics from its main references, and Piaget's theory. As a result, it was observed that the course that culminated in the current formalization of the analysis occurred in four stages: development of differential and integral calculus; organization of this calculus; analysis of this calculus; arithmetization of this analysis. Each of these stades parallels the notion of developmental stage, and the main difference between these stages would be the level of conceptualization. It is concluded that the learning of analysis takes place through successive moments of taking the awareness process that culminate in conceptualization. This implies that to present axioms and establish properties and theorems from them does not consist of a potential teaching activity, except for those students who already have reached the cognitive level necessary to carry out these assimilations and, therefore, the answer was already in the subject before. For those who have not reached that level, it is necessary to act on mathematical objects so that, from this action, the process of taking awareness of the concerned actions may occur. The aim was to contribute to broadening the debate about mathematics education in higher education, favoring a democratization of learning mathematics at all levels, including the most formal ones.
\end{abstract}

Keywords: Mathematical learning in higher education. Real analysis. History of mathematical. Genetic epistemology.

\title{
1 Introdução
}

As investigações em aprendizagem de Matemática são importantes para o campo da pesquisa em ensino dessa disciplina, pois é no entendimento sobre como se dá a aprendizagem dos conceitos que é possível planejar, com eficiência, as práticas de ensino. Entretanto, discussões como essa ocorrem em maior proporção quando tratadas no Ensino Básico (Fundamental e Médio). Posto isso, cabe o seguinte questionamento: o que se tem feito em termos de pesquisa em relação à aprendizagem dos conceitos de Matemática “avançados”, como aqueles discutidos no Ensino Superior?

A partir de experiências pessoais de docentes e discentes do Ensino Superior é possível constatar a grande dificuldade que muitos estudantes apresentam nas disciplinas de Matemática que cursam na graduação, tais como Cálculo (diferencial e integral), Álgebra Linear e Análise Real. Nesse contexto, percebe-se a necessidade de investigar como ocorre a aprendizagem nessas áreas, melhorando seu ensino. Assim, tem-se como propósito investigar a aprendizagem de conteúdos que pertencem a área da Análise Real, na perspectiva construtivista - área que foi escolhida tanto pela afinidade e interesse dos autores, quanto pela sua importância teórica e histórica na fundamentação da Matemática.

A linha teórica adotada como instrumento para discutir a aprendizagem é a epistemologia genética, pois esta teoria explica a gênese do conhecimento do sujeito desde o seu nascimento até a elaboração dos pensamentos formais do adulto, buscando entender o 
processo que o ser humano realiza para transformar um conhecimento simples em um conhecimento complexo. Pode-se entender como o raciocínio da análise matemática é construído e, portanto, compreender o processo de aprendizagem dos conteúdos pertencentes a esta área. Para isso, optou-se por utilizar a história da Matemática na compreensão da gênese da análise e da sua evolução histórica conceitual até o que se conhece hoje. Essa escolha se deu, pois entende-se que a história dos conhecimentos científicos pode dar pistas e indicações sobre o significado epistêmico da construção individual destes conceitos (PIAGET; GARCIA, 2011). Além da teoria de Piaget, buscou-se fundamentação também na história da Análise, a partir de obras que tratam da história da Matemática, como as escritas pelos clássicos pesquisadores Boyer e Merzbach (2012) e Eves (2004).

Com essas considerações, tendo como base a epistemologia genética e a história da Matemática, buscou-se obter hipótese teórica acerca de como se estruturam os saberes relacionados à Análise Real no sujeito. Delimitou-se como objetivo geral compreender o processo de construção dos conhecimentos da Análise Real na história, comparando-o ao desenvolvimento cognitivo do sujeito, sob a perspectiva da epistemologia genética. A fim de alcançar tal meta, elencou-se enquanto objetivos específicos: (i) compreender a construção histórica da Análise Real; (ii) estabelecer relações entre os estádios do desenvolvimento cognitivo de Piaget e a evolução dos conceitos referentes à Análise e; (iii) discutir a implicação destas relações na aprendizagem destes conceitos. As respostas a esses objetivos foram contempladas na descrição dos capítulos subsequentes.

\section{Aspectos metodológicos}

Antes de discutir a evolução histórica da análise e sua relação com o desenvolvimento cognitivo, convém fazer considerações metodológicas acerca do percurso tomado. Este estudo tem natureza teórica, bibliográfica, não sistemática e busca elencar aspectos teóricos da construção da Análise matemática na sua perspectiva histórica, relacionando-os ao processo de construção do conhecimento. Para essa análise, foi considerado determinado percurso de exame e de reflexão disponíveis no material histórico presente nos livros mais utilizados e de maior tradição em cursos de história da Matemática, até onde se sabe, Boyer e Merzbach (2012) e Eves (2004). Também, essa escolha é dada considerando a inexistência de estudos específicos no Portal de Periódicos da Capes e no Google Acadêmico no momento em que esta pesquisa foi realizada. 
Ainda, é necessário entender quais informações referentes à construção histórica dos conceitos da Análise são relevantes para compreender a aprendizagem desta área. A epistemologia genética parte da ideia de que, embora o ritmo do desenvolvimento cognitivo de cada indivíduo ou de grupos de indivíduos, possa ser diferente (segundo a ação de fatores internos e externos), a ordem de construção das diversas estruturas cognitivas será sempre a mesma (PIAGET; GARCIA, 2011). Então, compreender a natureza e as características das estruturas cognitivas propostas por Piaget possibilita ao estudioso ter noção de como um indivíduo, enquanto sujeito, constrói o conhecimento ao longo do tempo.

Sabendo que "a ação está, sempre, duplamente amarrada: amarrada pelas condições atuais dos sujeitos (indivíduos sob o ponto de vista psicológico) e amarrada pelas condições do meio que, nesse momento, envolve o sujeito" (BECKER, 2012, p. 55), tem-se que a construção de conhecimentos está atrelada ao desenvolvimento da estrutura cognitiva e que toda e qualquer ciência é construída social e historicamente por sujeitos. Portanto, em qualquer área do saber, os conceitos relacionados estão imersos em contexto histórico-social que, por sua vez, está imerso em diversos contextos cognitivos, permitindo que, conhecendo um destes contextos, seja possível aferir o outro.

Porém, para tomar tal percurso, é importante não se ater às influências pontuais dos pesquisadores em termos individuais e factuais, mas sim em caracterizar os períodos sucessivos do desenvolvimento destes conceitos ou das estruturas, construídos ao longo da história do conhecimento (PIAGET; GARCIA, 2011). Por isso, o foco investigativo foi a existência e sucessão de etapas históricas da evolução da Análise, entendendo o que marca a sucessão de uma etapa para a outra, e não apenas descrevendo a etapa em si. Compreendendo essas etapas, é necessário analisar a transição entre elas, utilizando os conceitos da epistemologia genética e estabelecendo conexão entre a evolução histórica e a aprendizagem humana individual.

\section{A Construção histórica dos conceitos referentes à Análise}

A Análise Real começou a ser discutida a partir do século XVIII, à medida que se percebeu a necessidade de construir uma base mais rigorosa para o Cálculo Diferencial e Integral (EVES, 2004). Então, seria negligente abordar sua história sem falar da história do Cálculo e, portanto, dos problemas que motivaram sua criação. Para isso, é necessário retroceder drasticamente no tempo, de modo a observar coerência em relação às perspectivas psicogenética e sociogenética da epistemologia genética. O Quadro 1 sintetiza a evolução 
histórica que culminou na criação da Análise como é conhecida atualmente, com informações sintetizadas a partir dos estudos de Eves (2004) e Boyer e Merzbach (2012).

\begin{tabular}{|c|c|}
\hline Estudiosos e Cientistas & Construções Matemáticas \\
\hline $\begin{array}{l}\text { Egípcios (antes de } 1800 \text { a. C.) e os } \\
\text { matemáticos gregos: Antífon, } \\
\text { Anaxágoras, Hipócrates, Hípias de } \\
\text { Elis, Eudoxo e Arquimedes (todos } \\
\text { entre } 400 \text { a. C. e } 200 \text { a. C.) }\end{array}$ & $\begin{array}{l}\text { Tentativas de obter a quadratura do círculo. Isto é, dado um círculo } \\
\text { qualquer, quer-se construir um quadrado que possua a mesma área } \\
\text { deste círculo, utilizando como ferramenta matemática apenas régua e } \\
\text { compasso. Porém, sem conseguir resolver apenas com esses } \\
\text { instrumentos, buscou-se utilizar aproximações. }\end{array}$ \\
\hline $\begin{array}{l}\text { Eudoxo, na criação e aprimorado por } \\
\text { Arquimedes }\end{array}$ & $\begin{array}{l}\text { Utilização do método da exaustão para resolver quadraturas (desde a } \\
\text { do círculo, até de figuras "menos triviais", como parábolas). Este } \\
\text { método consiste em medir áreas por meio da inscrição de polígonos } \\
\text { na figura desejada, aumentando a quantidade de lados deste } \\
\text { polígono, de modo que a medida de sua área se torne tão próxima } \\
\text { quanto se queira da medida da área que se deseja calcular. Por } \\
\text { exemplo, na quadratura do círculo, procede-se inscrevendo polígonos } \\
\text { regulares de } n \text { lados e estudando o que ocorre com a área dos } \\
\text { polígonos quando o número de lados tende ao infinito. }\end{array}$ \\
\hline Arquimedes & $\begin{array}{l}\text { Definição de uma espiral por meio da extremidade de um raio cujo } \\
\text { tamanho varia uniformemente com a inclinação (ângulo), obtida ao } \\
\text { tentar realizar a trissecção do ângulo. Então, com a direção do } \\
\text { movimento dos pontos que compõem a espiral, encontrou-se a reta } \\
\text { tangente à curva. }\end{array}$ \\
\hline $\begin{array}{l}\text { Simon Stevin (1548-1620) e Luca } \\
\text { Valério }(1552-1618)\end{array}$ & $\begin{array}{l}\text { Realização, a partir de abordagens inspiradas no método da exaustão, } \\
\text { da ideia de "passar o limite em ambos os lados da igualdade", que } \\
\text { consiste em um argumento prático e didático, utilizado até hoje em } \\
\text { muitos cursos de cálculo para simplificar o processo. }\end{array}$ \\
\hline Johannes Kepler (1571-1630) & $\begin{array}{l}\text { Cálculo da área de elipses (envolvidas no estudo das órbitas } \\
\text { planetárias), por meio de aproximações por triângulos. }\end{array}$ \\
\hline $\begin{array}{l}\text { René Descartes (1596-1650) e Pierre } \\
\text { de Fermat (1607-1665) }\end{array}$ & $\begin{array}{l}\text { Criação de métodos práticos para obter retas tangentes a curvas } \\
\text { planas (nesse caso, curvas descritas por equações). Criação da } \\
\text { Geometria Analítica (por Descartes), permitindo aritmetizar a } \\
\text { Geometria e geometrizar a Álgebra. }\end{array}$ \\
\hline John Wallis (1616-1703) & $\begin{array}{l}\text { Definição de integral como a área sob uma curva plana, apenas por } \\
\text { métodos geométricos. }\end{array}$ \\
\hline Isaac Barrow (1630-1677) & $\begin{array}{l}\text { Percepção de que há uma relação entre o problema das áreas } \\
\text { (quadratura de qualquer figura "curva") e o das tangentes. }\end{array}$ \\
\hline Isaac Newton (1643-1727) & $\begin{array}{l}\text { Criação do método dos fluxos, que consistia em conceber qualquer } \\
\text { curva como sendo a união de pontos em movimento. Assim, } \\
\text { conseguiu-se êxito em sistematizar as noções de limite, derivada e } \\
\text { integral, relacionando-as entre si (com um simbolismo matemático } \\
\text { adequado) e aplicando-as à dinâmica (criando as leis de Newton). }\end{array}$ \\
\hline
\end{tabular}




\begin{tabular}{|c|c|}
\hline $\begin{array}{l}\text { Gottfried Wilhelm Leibniz (1646- } \\
\text { 1716) }\end{array}$ & $\begin{array}{l}\text { Estabelecimento de importantes resultados do cálculo, como } \\
\text { fórmulas de derivação e integração utilizadas até hoje, de maneira } \\
\text { paralela aos estudos de Newton }{ }^{1} \text {. Criação de muitas das notações } \\
\text { matemáticas atuais, como o S alongado }(\delta \text { ) para integrais (da palavra } \\
\text { latina summa, que significa soma) e os infinitesimais } d y \text { e } d x \text {, que } \\
\text { permitem escrever a derivada como a razão } d y / d x \text {. }\end{array}$ \\
\hline Leonhard Euler (1707-1783) & $\begin{array}{l}\text { Ampliação dos métodos criados por Newton e por Leibniz e criação } \\
\text { de boa parte das notações atuais de cálculo, a partir da ideia de } \\
\text { função. }\end{array}$ \\
\hline $\begin{array}{l}\text { Jean-le-Rond d'Alembert } \quad(1717- \\
\text { 1783) }\end{array}$ & $\begin{array}{l}\text { Constatação da necessidade de uma boa teoria dos limites para } \\
\text { fundamentar adequadamente as operações de integração (cálculo da } \\
\text { área sob a curva) e de derivação (cálculo da taxa de variação ou da } \\
\text { inclinação da reta tangente à curva). }\end{array}$ \\
\hline Joseph Louis Lagrange (1736-1813) & $\begin{array}{l}\text { Busca por uma base matemática rigorosa ao Cálculo, tentando retirar } \\
\text { o conceito de limite da definição de derivada (sem sucesso). }\end{array}$ \\
\hline Bernhard Bolzano (1781-1848) & $\begin{array}{l}\text { Construção de resultados importantes para a teoria das funções } \\
\text { contínuas e para a noção de conjunto infinito (ambos necessários à } \\
\text { fundamentação do Cálculo). Porém, suas contribuições foram } \\
\text { reconhecidas tardiamente. }\end{array}$ \\
\hline Carl Friedrich Gauss (1777-1855). & $\begin{array}{l}\text { Realização de contribuições para que o rigor matemático fosse mais } \\
\text { valorizado dentre os matemáticos posteriores. }\end{array}$ \\
\hline Augustin-Louis Cauchy (1789-1857) & $\begin{array}{l}\text { Definição de limite e de continuidade muito parecida com as atuais. } \\
\text { Definição de integral como um limite de somas, tendo uma definição } \\
\text { formal, porém com forte apelo à visão geométrica do gráfico da } \\
\text { função e não apenas a sua estrutura (continuidade). }\end{array}$ \\
\hline $\begin{array}{l}\text { Karl Weierstrass }(1815-1897) \text { e } \\
\text { Georg Bernhard Riemann (1826- } \\
\text { 1866) }\end{array}$ & $\begin{array}{l}\text { Obtenção de exemplos de funções que contradiziam a intuição da } \\
\text { época. Weierstrass obteve uma função contínua que é não derivável } \\
\text { em todos os pontos. Riemann obteve uma função contínua para todos } \\
\text { os valores irracionais, mas descontínua para todos os valores } \\
\text { racionais. Percepção de que não poderia ser feita uma boa teoria dos } \\
\text { limites sem que a Análise fosse aritmetizada (fundamentação } \\
\text { rigorosa para o conceito de número real), para que os analistas } \\
\text { parassem de se basear na geometria das curvas e nos gráficos de } \\
\text { funções. }\end{array}$ \\
\hline $\begin{array}{l}\text { Richard Dedekind (1831-1916) e } \\
\text { Georg Cantor (1845-1918) }\end{array}$ & $\begin{array}{l}\text { Fundamentação dos números reais, enunciando a propriedade de } \\
\text { continuidade da reta real, como o axioma de Cantor-Dedekind. } \\
\text { Cantor estabeleceu e fundamentou os diferentes tipos de infinitos, } \\
\text { criando a ideia de enumerabilidade e não-enumerabilidade de } \\
\text { conjuntos, feita com base nos trabalhos de Dedekind. }\end{array}$ \\
\hline Giuseppe Peano (1858-1932) & $\begin{array}{l}\text { Estabelecimento dos axiomas de Peano, que fundamentam os } \\
\text { números naturais em lógica matemática. }\end{array}$ \\
\hline
\end{tabular}

Quadro 1 - Ações dos matemáticos para a criação do Cálculo e fundamentação do Cálculo, conhecida como Análise, na história da Matemática

Fonte: Elaborado pelos autores (2019)

\footnotetext{
${ }^{1}$ Embora, na época, a simultaneidade dos trabalhos de Newton e Leibniz tenha sido interpretada como cópia por parte de algum deles (interpretação que muitos têm até hoje), entende-se que ambos estabeleceram seus resultados independentemente, sendo a eventual rivalidade não saudável para compreender historicamente os avanços da matemática (EVES, 2004).
} 
Conforme descrito no Quadro 1, o Cálculo surgiu a partir da exploração e da busca por solução de problemas bem antigos, já a Análise surgiu de um esforço de fundamentar o que foi construído pelo Cálculo. Ainda há muitas construções que serão importantes posteriormente, como a criação da Integral de Lebesgue ou as discussões sobre os fundamentos da Matemática. Porém, entende-se que, para o propósito do presente artigo, as discussões sobre estas construções não são necessárias.

Dessa forma, no Quadro 1 foram descritas atividades de cientistas para criar o Cálculo e a Análise tal como estudamos hoje, o que se fez delineando elementos da história da Matemática. Para ter instrumentos teóricos que permitam realizar tal discussão, é necessário contextualizar a construção do conhecimento, sob a luz da epistemologia genética.

\section{A construção do conhecimento segundo a epistemologia genética}

A epistemologia genética é a teoria que entende a aquisição de conhecimentos como processo de construção ativo, fruto da interação sujeito-objeto, sendo o objeto tudo aquilo que é conhecível pelo sujeito, do ponto de vista epistemológico, inclusive ele próprio. Se a construção do conhecimento, para Piaget, é processo ativo, dado a partir da interação sujeitoobjeto, os estudiosos da aprendizagem podem, seguindo os pressupostos piagetianos, supor que a aprendizagem não é estática, pondo a ação do sujeito no centro do processo que, por isso, é concebido como construção.

Para Piaget, a construção de novos conhecimentos é vista como adaptação, processo pelo qual o sujeito, em sua interação com o objeto, necessita modificar sua estrutura cognitiva prévia (processo de acomodação) para poder assimilar (processo de assimilação) informações novas, o que, por sua vez, resulta em novo patamar de organização e de adaptação ao objeto. Afinal, "a inteligência é uma adaptação", o que significa dizer que a função da inteligência é "estruturar o universo tal como o organismo estrutura o meio imediato" (PIAGET, 1978b, p. 15). Portanto, para explicar a construção do conhecimento, é necessário entender a organização das estruturas de assimilação do mundo exterior que, ao mesmo tempo que a ele se adaptam, se transformam e transformam-no.

Em resumo, o sujeito age sobre o objeto e tenta apreendê-lo, a partir do que suas estruturas prévias proporcionam, caracterizando processo de assimilação. Contudo, é necessário reestruturá-las para se adaptar aos novos conhecimentos, em processo de acomodação do que foi assimilado. A “adaptação só se considera realizada quando atinge um 
sistema estável, isto é, quando existe equilíbrio entre a acomodação e a assimilação" (PIAGET, 1978b, p. 18).

Esse equilíbrio é dinâmico, jamais sendo atingido de maneira estática, pois cada novo equilíbrio torna o sujeito capaz de realizar assimilações que não haviam sido feitas anteriormente, tornando-o suscetível a novos desequilíbrios. Embora saliente-se que a construção do conhecimento é um processo de equilibração e adaptação às perturbações do meio, o sujeito precisa ter estrutura capaz de suportar essas perturbações ou o ciclo de assimilação pode se romper, resultando na não adaptação do organismo (PIAGET, 1978b).

É necessário, antes de prosseguir, dar noção mais precisa sobre o que se entende por instrumentos mentais que o sujeito tem à sua disposição, conhecidos em sua totalidade como estrutura cognitiva. O constructo "estrutura cognitiva", enquanto totalidade dinâmica, em constante alteração - sistema aberto - é central nas proposições de Piaget sobre o desenvolvimento cognitivo, vindo, assim, a ser um dos pilares da epistemologia genética. Segundo Becker e Marques (2012, p. 159), “estrutura é uma organização interna, não apenas cognitiva e psicológica, mas também e fundamentalmente biológica”.

A estrutura cognitiva traduz as formas de assimilação do sujeito em relação aos objetos, sendo que, inicialmente, ela é sensório-motora. Com o tempo e com as devidas construções feitas, tornar-se-á estrutura operatória, inicialmente concreta e depois formal. Primeiro, as estruturas operatórias são de ordem operatório-concreta, pois possibilitam ao sujeito elaborações reversíveis, mas se, e somente se, apoiadas em manipulações concretas das relações implicadas (pensamento de primeira ordem). Adiante no processo de desenvolvimento, as estruturas operatórias passam a ser operatório-formais, possibilitando ao sujeito elaborar relações somente com apoio nas representações dessas relações representação da representação (pensamento de segunda ordem), como é o caso da Análise Real.

\subsection{As abstrações e o processo de conceituação}

Tendo em vista que a ação possui papel central na construção de conhecimento, convém entender as diferentes experiências que o sujeito tem ao agir sobre um objeto, isto porque, a experiência é concebida como "ação do sujeito sobre os objetos e a reação destes sobre o sujeito" (BECKER, 2010, p. 213). Essa noção de experiência enriquece as concepções de assimilação e acomodação. Para isso, porém, é necessário diferenciar os dois tipos de experiência que Piaget utiliza: experiência física e experiência lógico-matemática. 
Paralelamente a isso, tratar-se-á do conceito de abstração, pois ambos os tipos de experiência se apoiam em abstrações de diferentes tipos.

O significado de abstração diz muito sobre o que se entende por esse conceito na epistemologia genética, embora não revele tudo. Para Piaget et al. (1995, p. 301), “[...] a abstração consiste em acrescentar relações ao dado perceptivo e não apenas em extraí-las dele". Para reconhecer qualidades comuns aos objetos (tal como a cor), não basta simplesmente reconhecer esta característica perceptivamente (amarelo, por exemplo). É necessário constituir estrutura cognitiva capaz de entender que esta propriedade é comum a outros objetos, uma estrutura de assimilação.

A abstração simples, ou empírica, consiste em extrair informações dos objetos enquanto tais, ou, extrair das ações do sujeito sobre suas características materiais (PIAGET et al., 1995). Convém ressaltar que isso não significa fazer leituras perceptivas dos objetos, pois, para abstrair, é necessário utilizar instrumentos de assimilação (estabelecimentos de relações, significações etc.) que foram construídos pelo sujeito anteriormente. A essa noção está atrelada a de experiência física, que consiste em "agir sobre os objetos para descobrir suas propriedades, tirando-as deles por meio de abstrações 'simples', a partir das informações perceptivas" (DOLLE, 1987, p. 62). Um exemplo seria a simples constatação de que um objeto possui determinada cor.

A abstração reflexionante, por outro lado, tem relação com as experiências lógicomatemáticas, sendo que essas experiências, ao contrário das experiências físicas, consistem em agir sobre os objetos e retirar informações das propriedades que essa ação introduz no objeto (DOLLE, 1987). Esta abstração comporta dois aspectos inseparáveis, o reflexionamento e a reflexão. O reflexionamento pode ser tido como a projeção sobre estrutura mais complexa daquilo que foi tirado de estrutura menos complexa. Já a reflexão é tida como a reconstrução e a reorganização sobre a estrutura mais complexa daquilo que foi transferido da mais simplificada (BECKER, 2012).

Além desses dois aspectos que constituem a abstração reflexionante, ela possui dois desdobramentos. Primeiro, se o objeto sofre modificações através da ação do sujeito e é enriquecido de propriedades tiradas das suas coordenações - como acontece quando, por exemplo, a criança verifica que possui $x$ carrinhos - diz-se, então, que ocorreu abstração pseudo-empírica. Nesse caso, a quantidade de carrinhos não é característica natural da coleção, mas sim, característica imposta pelo sujeito, que acaba por modificar o objeto (a coleção de carrinhos), atribuindo-lhes quantidade pela sua ação de contagem. Se o resultado de uma abstração reflexionante tornar-se consciente (em qualquer nível), tem-se uma 
abstração refletida. Segundo, e valendo-se do exemplo anterior, se a criança perceber que, independente da ordem em que agrupar os carrinhos, a quantidade não muda (associatividade e comutatividade), tal configura-se enquanto abstração refletida.

Do quadro complexo das abstrações empíricas e reflexionantes faz parte, necessariamente, o processo da tomada de consciência, pelo qual, continuamente (em todos os níveis de elaboração da inteligência), o sujeito se apropria dos mecanismos internos das coordenações da sua ação (BECKER, 2012). É nesse processo de tomada de consciência, portanto, que ocorre a evolução da abstração reflexionante à abstração refletida.

Ainda, por meio de progressivas tomadas de consciência das ações, tem-se a conceituação, isto é, o processo no qual o sujeito transforma sua ação em conceitos, tornandoo muito mais capaz de novas tomadas de consciência, fazendo com que as próprias ações futuras sejam modificadas. Por isso, o processo de tomada de consciência amplia qualitativamente a capacidade de coordenação das ações do sujeito (PIAGET, 1977), possibilitando conceituá-lo. Ou seja, toma consciência dos mecanismos que mobilizou para realizar essa ação. Por isso o matemático calcula, experimenta, simula para apenas depois refletir sobre os mecanismos mobilizados nestas ações, para somente então realizar axiomatização.

A abstração reflexionante possui criatividade própria da reflexão, que permite que, cada vez mais, propriedades e conexões entre propriedades sejam atribuídas aos objetos. Estas propriedades e conexões são o que constituem os saberes científicos de determinada área. Enfatiza-se que a Matemática não é ciência pronta e acabada, pois, considerando novas e contínuas abstrações reflexionantes realizadas, podem ser efetuadas novas e mais amplas generalizações, até mesmo sobre conhecimentos já constituídos.

A construção de conhecimentos ocorre como um processo de adaptação, no qual o sujeito retira as informações que é capaz dos objetos que consegue assimilar por abstração, isto é, retira aquilo que seus esquemas de assimilação permitem retirar. Então, acaba por ser necessária a modificação desses esquemas, o que se faz por processo de acomodação. Essa modificação pode colocar o sujeito em novo patamar do ponto de vista da estrutura cognitiva, que não é estática; ou seja, a partir de novos desequilíbrios, o sujeito assimilará e reconstruirá esta estrutura, tornando-a cada vez mais complexa.

Tendo como pano de fundo a dimensão do funcionamento da inteligência, passa-se à exposição sobre a teoria dos estádios da construção da inteligência, abordando aspectos mais específicos das mudanças estruturais que podem ocorrer no indivíduo, desde a construção da 
inteligência sensório-motora do bebê, até a construção do pensamento operatório-formal do adulto, a partir da adolescência.

\subsection{A Teoria dos estádios}

A teoria dos estádios ${ }^{2}$ do desenvolvimento cognitivo, no âmbito da epistemologia genética, explica o processo de construção das estruturas da inteligência do indivíduo, a partir do seu nascimento e conforme a ação dos fatores dessa construção admitidos por Piaget (maturação, experiência com o objeto, transmissões e interações sociais, processo de equilibração). Entende-se que a inteligência formal do adulto tem sua origem primeira na inteligência prática da criança, que se apoia nos hábitos e associações que são praticados desde o nascimento (PIAGET, 1978b).

Portanto, há um percurso de desenvolvimento que a inteligência de um indivíduo pode fazer desde seu nascimento até sua vida adulta e que se caracteriza por diferentes patamares, os estádios do desenvolvimento. É importante não atribuir o significado de período cronológico ao termo estádio (atribuindo-lhe o significado de estágio ou substituindo por essa palavra), pois a ideia do termo é enfatizar a noção de construção em etapas sucessivas e dependentes entre si. Justamente para evitar possíveis confusões, convém discutir os critérios que delimitam os estádios.

O primeiro critério de delimitação dos estádios é o da ordem de sucessão constante (invariável) com cronologia variável. A ordem de sucessão diz respeito à ordem de construção das estruturas da inteligência em que, por se tratar de construção psicogeneticamente apoiada nas estruturas anteriores, alguns esquemas são construídos antes dos outros, justamente por haver relação de dependência entre esses esquemas (DOLLE, 1987). Por exemplo, uma criança não desenvolverá o pensamento formal sem exercer suas experiências sensóriomotoras, pois saltar estádios seria contraditório com a noção de construção do conhecimento. Da mesma forma, como cada construção se faz como resultado de interações pessoais, únicas, pode-se ter alteração na cronologia de um estádio ou de outro. Algumas pessoas desenvolvem o pensamento formal mais cedo e outras mais tarde (sem que haja julgamento de inferioridade a qualquer delas). Além disso, por causa de defasagens horizontais, pode-se processar determinado conteúdo do conhecimento de modo formal, mas não outro conteúdo, de outra

\footnotetext{
${ }^{2}$ Etimologicamente, estádio tem origem do grego, stádion, que significava uma medida de aproximadamente 125 passos. Mais tarde, passou a ser utilizada para designar o lugar onde aconteciam práticas esportivas (que hoje se conhece por estádio) (BECKER, 2012).
} 
área, por exemplo. Deve-se abandonar os discursos do tipo "fulano já tem $x$ anos, então ele está no estádio y e deve ser ensinado da forma $z$ ”.

O segundo critério é o do caráter integrativo, significa afirmar que as estruturas construídas em estádio anterior são integradas às estruturas do nível seguinte (DOLLE, 1987). Ou seja, não se abandona o conhecimento nem a lógica construída nos estádios precedentes. Dessa maneira, percebe-se o equívoco de utilizar o termo “estágio", pois dá a ideia de período, com início e fim, que, portanto, ao final, será abandonado. O sujeito utiliza os conhecimentos construídos nos estádios que já superou, mas de forma diferente. Por exemplo, atletas, músicos instrumentistas, eletricistas, motoristas etc., utilizam suas motricidades de forma diferente de como utilizavam na infância.

Há analogia interessante a ser feita a partir da ideia do caráter integrativo dos estádios em relação à construção dos conhecimentos matemáticos, posto que as estruturas matemáticas surgem a partir de generalizações das estruturas simples. A estrutura complexa interioriza a estrutura simples, superando-a, mas não a abandonando. Na Matemática, a Análise é exemplo de estrutura complexa do Cálculo (como será discutido adiante). Mas um exemplo simples pode ser abordado. Quando se fala em vetores ortogonais em duas ou três dimensões, referese a vetores perpendiculares (com ângulo, no sentido geométrico, de $90^{\circ}$ entre eles). Porém, essa noção pode ser estendida, isto é, generalizada: dois vetores $n$-dimensionais, com $n$ sendo número natural não nulo, são ortogonais quando o produto interno (produto escalar) entre eles é nulo. Assim, quando $n$ é igual a dois ou a três essa definição coincide com a definição geométrica dada anteriormente.

O terceiro critério é o da noção de totalidade inerente à organização das estruturas. Um dos equívocos que se pode tomar ao se partir da noção de construção de conhecimento é conceber essa construção enquanto somatório de conteúdos que vão se agregando na mente do sujeito. A própria noção de estrutura, enquanto coordenação de esquemas, é contraditória à ideia de construção dos conhecimentos de forma somatória, pois essa construção ocorre pela aplicação dos esquemas à diversidade do meio, exigindo generalizações e, portanto, ampliando e transformando os esquemas (BECKER, 2012). Ou seja, a construção do conhecimento não é um somatório dos conhecimentos, mas sim complexificação de estruturas.

O quarto e último critério é o da noção de processo, que tem relação direta com a ideia de desenvolvimento cognitivo por estruturações sucessivas. Cada estádio comporta um nível de preparação para o estádio posterior e de acabamento por si mesmo (DOLLE, 1987). Isso é evidente quando se compreende a construção de conhecimento como processo de adaptação 
do sujeito aos objetos, em progressiva organização dessas formas de adaptação, segundo o modelo da equilibração. O equilíbrio cognitivo, que é o objetivo das condutas inteligentes, nunca é estático, pois prepara o sujeito para as assimilações futuras.

\subsubsection{Os estádios do desenvolvimento cognitivo}

Na sequência do texto foram abordados aspectos explicativos sobre os quatro estádios do desenvolvimento apresentados por Piaget (1978b). Uma abordagem mais completa pode ser encontrada em Becker (2010). A teoria dos estádios tem como objetivo explicar o percurso de desenvolvimento cognitivo do indivíduo.

O primeiro estádio é chamado de sensório-motor (PIAGET, 1978b). Com o exercício e o melhoramento da estrutura sensório-motora dos primeiros anos de vida, o sujeito será capaz de coordenar seu corpo (tomando consciência dessa estrutura) e utilizá-la para exercer seus primeiros esboços de linguagem (falando as primeiras palavras, por exemplo). Com isso, o sujeito passa a dispor da função simbólica, que permite "invocar" objetos que antes estavam ausentes, através de imagem mental pessoal própria ("mamã”, "papá”, “auau”) (DOLLE, 1987). Essa função simbólica, além de consistir em melhoramento da estrutura prática anterior, consiste em preparação para o estádio seguinte, pois, quando tomar consciência de que consegue evocar objetos ausentes, o sujeito será capaz de agir sobre esses objetos, constituindo estrutura pré-operatória de pensamento.

Esta inteligência pré-operatória (simbólica), ao permitir a evocação de objetos, dá ao sujeito capacidade de previsão de resultados na forma de intuição. Com as experiências sensório-motoras das quais o sujeito tomou consciência, ele constrói "repertório" que lhe permite tentar prever o resultado de suas ações. Porém, essa intuição será parcial, pois tem base sensorial, ao invés de base lógico-matemática (PIAGET, 2015). Após o exercício dessa intuição, o sujeito poderá tomar consciência dela, o que é feito através da construção de estrutura operatória.

Essa estrutura permite que a ação seja realizada mentalmente em seus dois sentidos de percurso, sendo que ações opostas se anulam por negação ou por reciprocidade, mas com consciência de que se trata de uma mesma ação (BECKER, 1999). Por isso, diz-se que uma das principais características dos estádios operatórios é a reversibilidade. Todavia, inicialmente, essa ação mental interna ocorre apoiada na manipulação concreta de materiais, propiciando a representação direta das ações e relações, fazendo com que esse estádio seja chamado de operatório concreto. 
Tomando consciência das operações concretas, o sujeito será capaz de agir sobre objetos mentais e hipotéticos por meio de operações formais, como ações mentais apoiadas nas representações das ações do plano concreto - representação da representação. Dessa maneira estará construída a estrutura das operações formais, na qual todo o pensamento científico se baseia. Essa estrutura de pensamento caracteriza o estádio chamado de operatório formal, a partir do qual o sujeito será capaz de realizar, cada vez mais, generalizações e abstrações, tal como ocorre na construção da Matemática de Ensino Superior.

Refletindo sobre a construção de conhecimentos de Matemática, enquanto disciplina, reforça-se a ideia de que se tem como hipótese que essa construção ocorre através de processos semelhantes aos descritos anteriormente. Mesmo as construções mais formais, como no caso da Análise Real ou das outras áreas da Matemática avançada, ocorrem por meio de ações sobre objetos, de abstrações e de tomadas de consciência sucessivas. A diferença é que, no nível formal, as operações ocorrem sobre representações de operações, não exclusivamente sobre manipulação concreta das ações. Afinal, "muito antes de verdades só atingíveis por uma linguagem abstrata, a matemática consiste em ações exercidas sobre as coisas, sendo as próprias operações também ações, porém coordenadas entre si e efetuadas no nível das representações" (BECKER, 2010, p. 206).

O que garante a existência desses objetos mentais, que seriam os objetos matemáticos, é a função simbólica, que começa a ser construída a partir do desenvolvimento da inteligência pré-operatória. À medida que o sujeito constrói o pensamento reversível, ele torna-se capaz de produzir elaborações sobre representações dos objetos, até o ponto que agirá sobre objetos mentais (alcançado com a reversibilidade completa, no estádio operatório formal), permitindo que sua ação ocorra com objetos hipotéticos.

Porém, essas ações mentais (operações), embora consistam em tomada de consciência dos instrumentos da ação física e prática, não implicam, imediatamente, em tomada de consciência das suas próprias coordenações. Ainda, agir sobre objetos mentais não implica em conceituação no sentido piagetiano. A tomada de consciência dessa ação ocorrerá depois, visto que a ação tem êxito ao resolver problemas antes de ser, ela própria, compreendida ou conceituada (BECKER, 2012).

Neste ponto da discussão, convém salientar que a conceituação, como fruto de processo de tomada de consciência que ocorre por meio de abstrações refletidas, é central na discussão aqui feita, pois os diferentes níveis de conceituação explicariam a evolução histórica da análise. Essas considerações convergem para o que foi observado durante o 
estudo teórico da história do Cálculo e da comparação desse caminho ao que deveria ser percorrido quando aprendidos os conceitos de Análise, a partir da epistemologia genética.

Durante esta construção, podem ocorrer a ação prática sobre os objetos, buscando simplesmente solucionar problemas. Pode acontecer o êxito total ou parcial obtido a partir da ação, ou modificações da estrutura - buscando corrigir as falhas para alcançar o equilíbrio cognitivo. Também pode ocorrer a repetição de ações até a obtenção do êxito, bem como a tomada de consciência dos instrumentos da ação, por meio de abstrações refletidas. Por fim, pode acontecer a conceituação, projetando em novo nível, construindo novos objetos mentais nos quais o ciclo continuará infinitamente. É justamente esse mecanismo que explica a grande quantidade de generalizações feitas na Matemática atual.

Tendo explicitado aspectos da evolução histórica da Análise e discutido o desenvolvimento cognitivo humano, buscou-se, a seguir, interpretar a história da Análise, a partir da epistemologia genética, com intuito de entender e contribuir com a aprendizagem desta área.

\section{A evolução da Análise Matemática e sua relação com o desenvolvimento cognitivo}

Considerando os diferentes patamares de conceituação, buscou-se estabelecer relações, a partir deste estudo teórico, entre as etapas de sucessão dos conceitos da Análise Real e a caracterização dos estádios do desenvolvimento cognitivo, sob a luz dos critérios de delimitação desses estádios. Este estudo comparativo pode ser visto como a proposição de hipótese a ser verificada. Dessa forma, com base no estudo feito sobre a construção destes conceitos na história da Matemática, identificou-se quatro etapas no desenvolvimento da Análise Real ${ }^{3}$ : a) o desenvolvimento do Cálculo Diferencial e Integral; b) a organização do Cálculo Diferencial e Integral; c) a análise do Cálculo Diferencial e Integral e; d) a aritmetização da Análise.

A primeira etapa consistiria no desenvolvimento do Cálculo Diferencial e Integral, que se desenvolveu como resposta prática aos problemas da quadratura e das tangentes, conforme descrito no Quadro 1. Do ponto de vista matemático, essa etapa é caracterizada pela ausência de conexão entre esses dois problemas. Conexão que foi devidamente explorada, pela

\footnotetext{
${ }^{3}$ Não se deve cometer o equívoco de estabelecer correspondência biunívoca (um a um) entre essas quatro etapas e os quatro estádios descritos por Piaget. Uma simples consideração que elimina esta interpretação é o fato de que os sujeitos de todas estas etapas mobilizaram estruturas operatórias, de graus diferentes, é claro, mas todas formais.
} 
primeira vez, por Newton e Leibniz, dando início à etapa posterior. Do ponto de vista cognitivo, a falta de conexão entre a ideia de integração (representada pelo problema da quadratura) e de derivação (representada pelo problema das tangentes) poderia indicar que esses processos não estariam devidamente consolidados e conceituados na forma de operações (a diferenciação e a integração), pois uma operação consiste de estrutura de totalidade das transformações reversíveis (PIAGET, 1976).

Essa primeira etapa (a) iniciou-se rompendo com a Geometria Estática grega, pelo método da exaustão de Eudoxo e Arquimedes (EVES, 2004). Ao observar esse método e os métodos para obtenção das retas tangentes em relação a curvas planas, mobilizados ao final da Idade Média (que foi a primeira abordagem ao problema das tangentes), nota-se a praticidade imediata na qual essa etapa está imersa, isto porque nenhum dos matemáticos citados preocupava-se com sua generalidade ou formalismo, buscando apenas resolver problemas específicos e pontuais.

Enquanto o método da exaustão permitia calcular a área de alguma figura "curva" por meio de aproximações poligonais, os métodos de obtenção de tangentes, propostos por Fermat e Descartes, calculavam a inclinação da reta tangente em ponto específico de uma curva polinomial. Ambos os métodos consistiam apenas em lista de passos que deveriam ser seguidos para a resolução do problema, sem tomada de consciência desses passos, o que permitiria conceituação, que poderia implicar em generalização desses métodos.

Além disso, a falta de conexão entre os dois problemas enunciados denuncia o fato de que os matemáticos, até o momento, não haviam tomado consciência dos instrumentos mobilizados nessas resoluções. Para que isso ocorresse, seria necessário que, por meio de ações (integrações e derivações) sobre os objetos (curvas planas), fossem realizadas abstrações reflexionantes (isto é, retirar informações das propriedades que estas ações causam nos objetos), até o ponto em que essas ações se tornassem conscientes, até a realização de abstrações refletidas.

Porém, para que fossem feitas estas abstrações, a integração e derivação teriam que ser vistas como processos locais e específicos, o que impediria que propriedades novas pudessem ser exploradas. $\mathrm{O}$ avanço para a etapa seguinte (b) parece ter ocorrido quando as abstrações refletidas foram elaboradas, permitindo esses processos (integração e derivação) fossem transformados em objetos (as derivadas e as integrais), consentindo operar sobre eles.

Vale mencionar que o fato de essa etapa, do desenvolvimento do Cálculo Diferencial e Integral, ser prática e anterior à formalização do cálculo, é coerente com a teoria de Piaget, afinal, há descompasso da conceituação em relação à ação (PIAGET, 1977) e do fazer em 
relação ao compreender (PIAGET, 1978a), pois a conceituação é obtida por progressivas tomadas de consciência dos mecanismos da ação (BECKER, 2012).

Os sujeitos dessa etapa (e de todas as posteriores) agem sobre objetos mentais, ação essa que ocorre na forma de operações (com todas as propriedades das operações formais). Porém, sabe-se por Piaget, que os sujeitos não possuem compreensão imediata dos mecanismos implícitos dessas ações, o que denuncia o fato de que a conceituação ainda não ocorreu. Isso pode ser percebido pela falta de conexão entre os problemas da quadratura e das tangentes (conexão essa que, embora tenha sido percebida por Isaac Barrow, foi devidamente estudada apenas com Newton e Leibniz, quando as tomadas de consciência da referida conexão poderiam ter ocorrido).

Algo que pode melhor corroborar tais ideias são as considerações de Piaget acerca da abstração reflexionante. Essa forma de abstração é, por si mesma, uma espécie de operação que retira informações a partir de coordenações das ações e das operações e projeta-as em patamar superior, aplicando-as de maneira nova (PIAGET et al., 1995). Primeiramente, os matemáticos teriam agido sobre figuras geométricas (objetos mentais) com seus métodos de integração e derivação (obtenção da quadratura e da reta tangente a partir de aproximações). Dessa maneira, a aplicação desses métodos pode ser compreendida como operações que teriam sido efetuadas sobre esses objetos mentais e geométricos. A partir do ponto em que tomadas de consciência sobre as coordenações dessas ações teriam ocorrido, seria possível estabelecer conceituações progressivas, até o momento em que tais ações seriam projetadas em patamar superior. Nesse caso, as operações tornar-se-iam objetos a permitir novas operações. Portanto, haveria analogia a respeito na transição entre o estádio operatório concreto e operatório formal, por meio da formação das estruturas operatórias.

Na história da Matemática, percebe-se isso quando os processos de integração e de derivação se transformam em objetos, as derivadas e as integrais, permitindo que ações e operações sejam feitas sobre eles. Poder-se-ia notar a repetição do ciclo neste patamar superior de conhecimento. Ou seja, com base no ciclo ação-conceituação-abstrações refletidas (PIAGET, 1977), assistir-se-ia à crescente quantidade de generalizações características da Matemática atual, da qual a Análise matemática faz parte enquanto generalização da Análise Real, que é generalização do Cálculo, afinal, a conceituação modifica a ação (BECKER, 2012). O trabalho de Newton e Leibniz não teria sido o de criar o cálculo, mas sim de transformá-lo em ciência matemática ao agir sobre objetos-ação de forma mais geral e abrangente que antes, estando, portanto, em patamar superior. A partir disso seria dado início à segunda etapa. 
A segunda etapa, de organização do Cálculo Diferencial e Integral, consiste na projeção, em estrutura superior, dos raciocínios mobilizados pelos métodos de cálculo de áreas e de tangentes utilizados anteriormente. Essa projeção consiste em abstrações que, ao tomar consciência dos métodos empregados, generalizam-nos e organizam-nos neste novo patamar, de forma a transformá-los, novamente, em objetos a serem aprendidos. Matematicamente, essa reorganização pode ser vista como axiomatização parcial, isto é, com as definições de derivada e integral criadas pelos matemáticos.

Essas definições podem ser feitas de diferentes formas, como o método dos fluxos de Newton ou como as razões infinitesimais de Leibniz. Com base nisso, os sujeitos seriam capazes de estabelecer novas relações, que seriam operações sobre os objetos desse novo patamar, uma vez que, com a conceituação, a ação passa a ser corrigida e melhorada (BECKER, 2012). Outra diferença importante entre essas duas etapas seria a de que, com a organização do cálculo, o sujeito parte do fazer ao compreender, visto que:

\section{Fazer é compreender em ação uma dada situação em grau suficiente para atingir os fins propostos, e compreender é conseguir dominar, em pensamento, as mesmas situações até poder resolver os problemas por elas levantados, em relação ao porquê e ao como das ligações constatadas e, por outro lado, utilizadas em ação (PIAGET, 1978a, p. 176).}

Porém, mesmo estando em patamar superior, essa compreensão dos métodos utilizados ainda pode ser parcial, como é o caso. Mesmo que os raciocínios mobilizados pelos organizadores do cálculo possam ser inovadores, eles ainda estavam impregnados de pensamentos intuitivos e geométricos, o que daria certa incerteza em algumas operações, principalmente pelo fato de que a noção de continuidade não tenha sido devidamente fundamentada (EVES, 2004). É interessante salientar que, da mesma forma que a imprecisão da intuição pré-operatória teria exigido que o sujeito, neste estádio, organizasse estruturas operatório-concretas (os diferentes agrupamentos), nesta etapa teria sido a imprecisão de algumas ações intuitivas dos matemáticos que fizeram com que o Cálculo exigisse uma reorganização.

Esta procura por novos meios de trabalhar com os conceitos do Cálculo teria exigido regulação das coordenações das ações que teriam sido feitas nessa etapa, ou seja, teria exigido nova tomada de consciência dos meios empregados. Na transição da segunda para a terceira etapa, teriam ocorrido processos muitos similares aos sucedidos na transição precedente, pois inadaptações são umas das razões que possibilitam a tomada de consciência (INHELDER; PIAGET, 1976). A conceituação dos meios empregados para as derivações e para as integrações, matematicamente, ocorre através das definições formais desses processos, bem 
como das definições formais de limite de sequências e de continuidade (todas elas eram bem parecidas com as utilizadas até hoje).

A terceira etapa, a Análise do Cálculo Diferencial e Integral, estaria em equilíbrio até o momento em que a noção de continuidade teria sido colocada em xeque, obtendo-se novas incoerências, que representam o desequilíbrio. Analogamente às outras duas transições que foram analisadas nesse processo histórico, a transição da terceira para a quarta etapa, a aritmetização da Análise, teria ocorrido por meio de tomadas de consciência, que levariam o sujeito da ação para a conceituação (sendo que essa projetar-se-ia como ação em um patamar superior).

O desequilíbrio cognitivo que teria iniciado esta transição pode ter ocorrido a partir dos exemplos de funções encontrados por Weierstrass e Riemann, que representaram incoerências com a formalização estabelecida até esta etapa. Enquanto Weierstrass obteve função contínua que não era derivável em ponto algum, Riemann obteve função contínua para todos os valores irracionais, mas que era descontínua para valores racionais. Estas funções colocam em xeque conceitos que eram aceitos, já que as definições feitas por Cauchy e por alguns outros matemáticos da etapa de Análise do Cálculo (c) eram altamente fundamentadas na noção geométrica dos números reais, ou seja, em conceito intuitivo de número real (EVES, 2004), o que gerava algumas incoerências por conta do desconhecimento das propriedades de continuidade deste conjunto numérico. Visto isso, para recuperar o equilíbrio, foi necessária a construção rigorosa e axiomática dos números reais e o estudo das propriedades do infinito, o que auxiliou na organização das estruturas construídas até o momento.

A hipótese central desse estudo, de que as imprecisões de algumas ações fundamentadas em noções intuitivas teriam exigido reorganização da Análise do Cálculo, faz analogia interessante com a construção da estrutura operatória conforme descrita na epistemologia genética, pois é imprecisão da intuição pré-operatória que exige reorganização das ações do sujeito na forma de operações (no caso, operações concretas). Portanto, a quarta etapa iniciar-se-ia com a conceituação da análise que, do ponto de vista histórico, ocorreu com o movimento de aritmetização da análise, isto é, a fundamentação do conceito de número.

$\mathrm{Na}$ quarta etapa, então, os sujeitos buscariam tomar consciência das propriedades envolvidas nos números reais e nos conjuntos infinitos. Para isso, realizar-se-ia, de forma similar, transições entre as etapas anteriores, abstrações reflexionantes, que se desdobrariam em abstrações refletidas, construindo tomadas de consciência que, sucessivamente, implicariam conceituações na forma de axiomatizações. Desse modo, teria sido possível 
construir os números reais com base nos números naturais, que foram construídos com base em lógica matemática, e estudar as propriedades dos conjuntos infinitos, com base nos diferentes tipos de infinitos. Definitivamente, essa etapa representa grande distanciamento das ideias intuitivas que deram origem ao Cálculo, do ponto de vista da história do sistema conceitual focalizado, sob ótica da epistemologia genética.

Estas quatro etapas descreveriam a evolução que ocorre desde o desenvolvimento do Cálculo, com base na resolução dos problemas das tangentes e da quadratura, até a aritmetização da Análise. Porém, as possibilidades de construção não se encerrariam por aí, visto que há áreas da Análise matemática que generalizaram os conceitos até o momento discutidos, como por exemplo, a teoria da medida e a análise $n$-dimensional.

Enquanto o sujeito for desafiado por novos desequilíbrios cognitivos, sua estrutura clamará por novas assimilações e acomodações, que, na forma de experiências sobre objetos matemáticos, manifestam-se enquanto abstrações reflexionantes. Com novas experiências, essas abstrações tendem a tornar-se refletidas (isto é, ter seus resultados conscientes) e, portanto, constituir conceituações, melhorando a estrutura de assimilação e de acomodação, transformando os objetos matemáticos. Dessa maneira, o ciclo descrito seria iniciado a cada novo conhecimento construído, sem fim absoluto, dando sequência ao desenvolvimento da Matemática, enquanto ciência.

\section{Conclusões}

Ao realizar esse percurso de estudo do desenvolvimento histórico conceitual da Análise Real sob o olhar do desenvolvimento cognitivo, na epistemologia genética, obteve-se a hipótese de que a Análise é construída com base em inúmeras e sucessivas tomadas de consciência dos instrumentos da ação matemática. É conhecido da epistemologia genética que o sujeito, quando já opera no nível formal (visto que deverá agir sobre os possíveis), agirá sobre objetos matemáticos e, caso mobilize processo de tomada de consciência dos instrumentos dessa ação (através de abstrações refletidas), buscará sistematização da matemática envolvida na sua ação. Essa sistematização, que representa a conceituação, na hipótese concluída pelo presente texto, apareceria matematicamente na forma de axiomatização, pois constitui lógica superior à da ação anterior, podendo desencadear novas ações conscientes, por dedução. Porém, essa axiomatização seria parcial, visto que o sujeito poderá tomar consciência das ações que serão feitas neste novo nível, iniciando o ciclo novamente. 
Dessas considerações, poderia emergir a ideia de que a axiomatização de um sistema matemático não representa potencial de aprendizagem para estudantes que ainda não tomaram consciência das ações que são limitadas por este sistema. Estando a axiomatização de um sistema matemático em patamar superior às operações (ações) que o sujeito realiza nos objetos deste sistema (isto porque axiomatização é fruto de conceituação que ocorre tardiamente em relação à ação, que, neste caso, é ação operatória por conta de ser ação reversível sobre objetos mentais e formais), ela serviria como objeto de ensino apenas para aqueles estudantes que já possuem a estrutura epistêmica necessária para assimilar estes axiomas.

Dado o caráter exploratório do presente estudo, considerando-o em formulação hipotética sobre a psicogênese do conhecimento em foco em estudantes do curso superior, tendo como referência a análise histórica, salienta-se a necessidade de serem feitas novas pesquisas que relacionam a epistemologia genética a diversas áreas da Matemática avançada. De tal modo, pesquisas que busquem entender e descrever as estruturas mentais mobilizadas em Análise ou em outras áreas da Matemática avançada, principalmente, são importantes para verificar, empiricamente, se há estádios complementares (isto é, estádios que surgem a partir das tomadas de consciência das operações formais que ocorrem na Matemática avançada). Salienta-se, então, a necessidade de verificação empírica da referida psicogênese, tendo como amostra estudantes de Matemática, enquanto elaboram tais conteúdos. As principais limitações da presente pesquisa referem-se ao seu método teórico-bibliográfico, dando espaço para a sequência desse estudo por meio de verificação das hipóteses levantadas, a partir de dados experimentais, de modo a corroborar ou reformular as conclusões obtidas com esse estudo.

Em relação à Educação Matemática, aponta-se para a importância que sejam feitas mais discussões sobre o ensino e a aprendizagem de tópicos da Educação Superior. Afinal, os processos de construção de conhecimento, em todos os níveis, dão-se através de adaptações e equilibrações. Torna-se necessário desmistificar o status “inacessível” dos saberes matemáticos em todos os níveis, sendo igualmente importante que essa ação ocorra, também, no Ensino Superior. Estudos com temáticas aliadas a essa auxiliam no ensino e na aprendizagem em cursos relacionados às ciências exatas, talvez até contribuindo na diminuição de índices de reprovação, e permitindo aprendizado ativo por parte dos estudantes. Além disso, urge a necessidade de desmistificar o status inacessível da Matemática, tornando o seu "fazer", mesmo em níveis altamente formais, tarefa possível a todos os sujeitos. 


\section{Referências}

BECKER, F. Educação e construção do conhecimento. 2. ed. Porto Alegre: Penso, 2012. 200 p.

BECKER, F. O caminho da aprendizagem em Jean Piaget e Paulo Freire: da ação à operação. Petrópolis: Vozes, 2010. 296 p.

BECKER, F. Epistemologia Genética e conhecimento matemático. In: BECKER, F.; FRANCO, S. R. K. (org.). Revisitando Piaget. Porto Alegre: Mediação, 1999. p. 21-48.

BECKER, F.; MARQUES, T. B. I. Estádios do desenvolvimento. In: BECKER, F. Educação e construção do conhecimento. 2. ed. Porto Alegre: Penso, 2012. p. 153-164.

BOYER, C. B.; MERZBACH, U. C. História da matemática. Tradução de Helena Castro. São Paulo: Blucher, 2012. 504 p.

DOLLE, J. M. Para compreender Piaget: uma iniciação à Psicologia Genética Piagetiana. 4. ed. Tradução de Maria José J.G. de Almeida. Rio de Janeiro: Guanabara Koogan, 1987. 202 p.

EVES, H. Introdução à história da matemática. Tradução de Higyno H. Domingues. Campinas: Editora da UNICAMP: 2004.

INHELDER, B.; PIAGET, J. Da lógica da criança à lógica do adolescente. Tradução de Dante Moreira Leite. São Paulo: Pioneira, 1976. 259 p.

PIAGET, J. et al. Abstração reflexionante: relações lógico-aritméticas e ordem das relações espaciais. Tradução de Fernando Becker e Petronilha Beatriz Gonçalves da Silva. Porto Alegre: Artes Médicas, 1995.

PIAGET, J. A tomada de consciência. Tradução de Edson Braga de Souza. São Paulo: Melhoramentos, 1977. $211 \mathrm{p}$.

PIAGET, J. Ensaio de Lógica Operatória. 2. ed. Tradução de Maria Angela Vinagre de Almeida. Porto Alegre: Globo, 1976. 393 p.

PIAGET, J. Fazer e compreender. Tradução de Christina Larroudé de Paula Leite. São Paulo: Melhoramentos, 1978a. $186 \mathrm{p}$.

PIAGET, J. O nascimento da inteligência na criança. Tradução de Álvaro Cabral. 3. ed. Rio de Janeiro: Zahar, 1978b. 389 p.

PIAGET, J. Seis estudos de psicologia. Tradução de Maria Alice Magalhães D'Amorim e Paulo Sérgio Lima Silva. 25. ed. Rio de Janeiro: Forense Universitária, 2015. 143 p.

PIAGET, J.; GARCIA, R. Psicogênese e história das ciências. Tradução de Giselle Unti. Petrópolis: Vozes, 2011. 376 p. (Coleção Textos Fundantes de Educação).

Submetido em 23 de Agosto de 2019. Aprovado em 11 de Abril de 2020. 